\title{
Agency and Relationship Dissatisfaction Associated with Orthorexia Symptomatology
}

\author{
Crystal D. Oberle, Shelby L. Lipschuetz \\ Department of Psychology, Texas State University, San Marcos, TX, USA \\ Email: oberle@txstate.edu
}

How to cite this paper: Oberle, C.D. and Lipschuetz, S.L. (2018) Agency and Relationship Dissatisfaction Associated with Orthorexia Symptomatology. Open Journal of Psychiatry, 8, 345-354.

https://doi.org/10.4236/ojpsych.2018.83027

Received: July 5, 2018

Accepted: July 28, 2018

Published: July 31, 2018

Copyright $\odot 2018$ by authors and Scientific Research Publishing Inc. This work is licensed under the Creative Commons Attribution International License (CC BY 4.0).

http://creativecommons.org/licenses/by/4.0/

(c) (i) Open Access

\begin{abstract}
This study explored whether orthorexia symptomatology is linked to gender-related personality traits and to levels of satisfaction in one's romantic relationships. Undergraduate students (418 women, 98 men) completed an online survey with measures to assess orthorexia symptomatology, agency, unmitigated agency, communion, unmitigated communion, and relationship satisfaction. Orthorexia symptomatology was positively correlated with levels of agency $(r=0.18 ; p<0.001)$, but it was unrelated to unmitigated agency ( $p$ $=0.51)$, communion $(p=0.76)$, unmitigated communion $(p=0.17)$, and relationship status $(p=0.99)$. Among the participants who were in a committed relationship, symptomatology was negatively correlated with relationship satisfaction $(p=0.01)$, and this correlation was most pronounced for those with higher levels of unmitigated agency $(p=0.01)$. Orthorexia is associated with the agency personality trait, indicative of one's need to be independent and to achieve personal accomplishments. However, particularly for those individuals whose agency becomes unmitigated, characterized by selfishness and avoidance of others, orthorexia symptomatology predicts significant dissatisfaction in romantic relationships.
\end{abstract}

\section{Keywords}

Orthorexia, Relationship Satisfaction, Agency, Communion

\section{Introduction}

Orthorexia nervosa (ON), originally defined by Bratman in 1997, outlines a condition that results in impaired functioning as a consequence of an obsessive fixation with eating "healthy" [1] [2] [3]. This obsessive fixation includes mental preoccupation and compulsive behavior regarding dietary restrictions that typically become more frequent and severe over time. According to experts in clini- 
cal practice and research on this condition, although the goals behind these restrictions are positive and include achieving optimal physical health and purifying the body, the results are often negative and may include malnutrition, intense negative feelings such as shame upon violating any of their dietary rules, or problems either with their academic or vocational work or with their social relationships [1] [2] [3].

Although no study has empirically investigated impaired social functioning in individuals with $\mathrm{ON}$, problems in this area are conceivable based on multiple factors. First, given their strict and restrictive dietary rules, they likely avoid restaurants and social gatherings that involve food, with either the knowledge or assumption that healthy options will not be available. Eating is a social behavior in many cultures, and avoidance of gatherings that involve eating may lead to social isolation from family, friends, and romantic partners. Second, as described below, ON symptomatology is correlated with several personality traits that happen to be associated with problematic relationships.

A consistent and established finding in the literature is a positive correlation between ON symptomatology and obsessive-compulsive tendencies [4] [5] [6] [7] [8]. This relationship makes sense, considering that the ON individuals' obsessions and compulsions with eating healthy extend to what, how, and when they eat, as well as to other domains that include exercise [9]. Unfortunately, obsessive-compulsive symptoms are also linked to difficulties with interpersonal relationships that include lower levels of intimacy and relationship satisfaction [10], as well as rigidity in the context of self-interest, need for excessive control over their partner, and overall an avoidant attachment style [11] [12].

ON symptomatology has further been positively correlated with the personality traits of perfectionism, narcissism [13], and neuroticism [7] [14]. The former research found that people who express ON symptoms have greater feelings of superiority, both in general and specific to their eating habits and behaviors, when compared to others. Regarding the latter research, neuroticism is a personality trait with a tendency toward a negative emotional state that includes feelings of depression, anxiety, and anger. Given that $\mathrm{ON}$ entails a time-consuming obsession that may consequently interfere with academic or vocational work, in addition to the feelings of guilt and shame that result from dietary lapses, feelings of negativity that include depression are certainly plausible. Unfortunately, relationship satisfaction is negatively correlated with all of these personality dimensions: perfectionism [15] [16], narcissism [17] [18] [19], and neuroticism [20] [21] [22]. By extension, we may then hypothesize that ON symptomatology would, likewise, be associated with lower levels of relationship satisfaction.

Also relevant to relationship satisfaction are the gender-related personality traits of communion and agency. Communion refers to the desire to form and preserve supportive interpersonal relationships with other people, whereas agency refers to the desire to be independent of others and to achieve personal accomplishments for oneself [23] [24]. Not surprisingly, past research reveals that relationship quality and satisfaction are positively related to communion 
with its emphasis on building supportive relationships [25] [26] [27] [28], but negatively related to agency with its emphasis on the self [26] [29].

The current study examines whether ON symptomatology is related to communion, agency, and satisfaction in romantic relationships. Regarding the personality traits, given that people with ON are very independent and focused on themselves with both their eating and exercise behaviors, we hypothesize that ON symptomatology would be positively associated with levels of agency. Regarding relationship satisfaction, given that $\mathrm{ON}$ is associated with other personality traits that are linked to lower relationship satisfaction (obsessive-compulsiveness, perfectionism, narcissism, and neuroticism), we hypothesize that ON symptomatology would be negatively associated with levels of relationship satisfaction among those who are currently in a committed relationship. Exploratory analyses will additionally be conducted to determine whether ON symptomatology differs between people who are single or in a committed relationship, and to determine whether the association between ON symptomatology and relationship satisfaction is moderated by gender or by the gender-related personality traits.

\section{Method}

\subsection{Participants}

This study's participants were 516 students ( 418 women, 98 men) enrolled in various undergraduate psychology courses at a large university in the southern region of the United States during the Fall semester. Their ages ranged from 18 to 41 years $(M=19.80, S D=2.52)$. Based on self-reported ethnicity, $40 \%$ were Caucasian, 37\% were Hispanic or Latino, 14\% were African American, 5\% were Asian American, 3\% were biracial or multiracial, and 1\% were of another ethnicity. The only exclusionary criterion was that participants had to be at least 18 years old.

\subsection{Materials and Procedure}

This study's methodology was approved by the Institutional Review Board of Texas State University. Upon providing informed consent, all participants completed an anonymous online survey with the scales that are described below, as well as a demographic questionnaire that included an item asking participants to indicate whether they were currently single and not dating anyone, casually dating one or more people, or in a committed relationship.

ON symptomatology was assessed with the Eating Habits Questionnaire (EHQ), a measure that includes 21 statements to which participants respond with a Likert rating indicating how well each statement represents their current eating habits ( $1=$ not at all true, $2=$ slightly true, $3=$ mainly true, $4=$ very true $)$ [7]. Some of the statements pertain to healthy eating behaviors (e.g., "I follow a health-food diet rigidly," "I prepare food in the most healthful way"), some pertain to problems that are associated with healthy eating (e.g., "I am constantly 
distracted by thoughts of eating healthily," "My healthy eating is a significant source of stress in my relationships"), and some pertain to feeling positively about healthy eating (e.g., "Eating the way I do gives me a sense of satisfaction," "I feel in control when I eat healthy"). This scale has demonstrated excellent internal consistency with Cronbach's alpha of 0.90 [13] and good test-retest reliability with coefficients ranging from 0.72 to 0.81 [7]. In addition, the authors of this questionnaire demonstrated the validity of the EHQ, finding its scores positively correlated with higher levels of both disordered eating behaviors and obsessive-compulsive tendencies, consistent with past research that found these same correlations but with a different measure of ON symptomatology [4] [5] [6] [8] [30] [31] [32].

The personality variables were assessed with the Personal Attributes Questionnaire (PAQ) [33] and the Revised Unmitigated Communion Scale (RUCS) [34]. The PAQ includes 24 sets of contradictory statements to which participants select a response indicating where they fall on 5-point scale between the two extremes. Eight of the sets pertain to agency (e.g., "Not at all independent ... Very independent," "Gives up easily ... Never gives up"), eight to unmitigated agency (e.g., "Not at all arrogant ... Very arrogant," "Not at all greedy ... Very greedy"), and eight to communion (e.g., "Not at all helpful to others ... Very helpful to others," "Very cold in relations with others ... Very warm in relations with others"). These agency, unmitigated agency, and communion subscales have been shown to be internally consistent with Cronbach's alphas of $0.76,0.72$, and 0.76 , respectively [35]. The RUCS includes nine statements to which participants respond on a 4-point Likert rating scale indicating their degree of agreement with the statements (e.g., "I always place the needs of others above my own," "For me to be happy, I need others to be happy"). This scale has been shown to be internally consistent with Cronbach's alpha of 0.74 [35].

Finally, relationship satisfaction was assessed with the Relationship Assessment Scale (RAS) [36]. For the RAS, participants use a 5-point Likert rating scale to answer seven questions about their current romantic relationship. Example questions are, "In general, how satisfied are you with your relationship?" and "How well does your partner meet your needs?" This scale has been shown to be internally consistent with Cronbach's alpha of 0.86 [36].

\subsection{Statistical Analyses}

First, Pearson correlation analyses were used to assess the relationships between ON symptomatology (EHQ scores) and each personality variable: agency (PAQ-Agency scores), unmitigated agency (PAQ-Unmitigated Agency scores), communion (PAQ-Communion scores), and unmitigated communion (RUCS scores). Second, an ANOVA was conducted to determine if ON symptomatology differed between participants who were single, casually dating, or in a committed relationship. Finally, for the 212 participants who reported being in a committed relationship, a regression analysis was conducted to assess the relation- 
ship between ON symptomatology and relationship satisfaction (RAS scores), and to determine if this relationship was moderated by gender or by any of the personality variables. For this analysis, the individual predictor variables (ON symptomatology, agency, unmitigated agency, communion, unmitigated communion, and gender: a dummy variable with men coded 0 and women coded 1) were first mean-centered, and the following interaction terms were subsequently computed: ON x gender, ON x agency, ON x unmitigated agency, ON x communion, and $\mathrm{ON} x$ unmitigated communion. The mean-centering of the predictor variables was effective at reducing multicollinearity between the interaction term and the individual predictor variables in the regression analyses (all tolerance values $>0.5$ and all VIF values $<2$ ). Note that this regression analysis was not used for modeling purposes, but simply as a statistical tool that is equivalent to ANOVA but appropriate in cases of continuous predictor variables and dummy categorical predictor variables.

\section{Results}

ON symptomatology was significantly correlated with agency $(r=0.18, p<$ $0.001)$, but not with unmitigated agency $(r=-0.03, p=0.51)$, communion $(r=$ $0.01, p=0.76)$, or unmitigated communion $(r=0.06, p=0.17)$. Further, ON symptomatology did not significantly vary between those who were single $(M=$ $38.40, S D=9.31)$, casually dating $(M=38.44, S D=8.18)$, or in a committed relationship $(M=38.40, S D=8.99), F(2,513)=0.001, p=0.999$. Finally, among the participants in a committed relationship, ON symptomatology was negatively associated with relationship satisfaction, and this relationship was moderated by unmitigated agency, such that the negative ON-relationship satisfaction relationship was most pronounced for those with higher levels of unmitigated agency (see Table 1).

Table 1. Regression analysis predicting relationship satisfaction from ON symptoms, gender, and personality.

\begin{tabular}{cccccc}
\hline & $B$ & $S E$ & $\beta$ & $t$ & $p$ \\
ON & -0.09 & 0.03 & -0.18 & -2.49 & $0.014^{*}$ \\
Gender & -0.34 & 0.89 & -0.03 & -0.39 & 0.696 \\
Agency & 0.11 & 0.07 & 0.12 & 1.67 & 0.096 \\
Unmitigated Agency & 0.08 & 0.07 & 0.08 & 1.05 & 0.296 \\
Communion & 0.21 & 0.08 & 0.23 & 2.68 & $0.008^{* *}$ \\
Unmitigated Communion & -0.08 & 0.09 & -0.07 & -0.93 & 0.355 \\
ON x Gender & -0.01 & 0.11 & -0.01 & -0.10 & 0.923 \\
ON x Agency & -0.01 & 0.01 & -0.11 & -1.49 & 0.138 \\
ON x Unmitigated Agency & 0.02 & 0.01 & 0.21 & 2.67 & $0.008^{* *}$ \\
ON x Communion & 0.02 & 0.01 & 0.16 & 1.85 & 0.066 \\
\hline ON x Unmitigated Communion & 0.01 & 0.01 & 0.08 & 1.07 & 0.287 \\
\hline O.05. ${ }^{* *}$ p $<0.01$. & & & & &
\end{tabular}




\section{Discussion}

The first purpose of the current study was to determine whether ON symptomatology is linked to the gender-related personality traits of agency or communion. According to personality researchers, those who align more with agency tend to focus more on themselves and maintain separation, while those who align more with communion are better connected with others, as they focus on these relationships more readily and see themselves as part of a collective or whole rather than as an individual unit [37]. As expected, symptomatology was positively correlated with levels of agency and unrelated to communion. People with ON are very independent and focused on themselves with both their eating [1] [2] and exercise behaviors [9], and apparently, these forms of independence are part of a more inclusive personality trait that encompasses the drive to be independent of others and to achieve personal goals and accomplishments across domains.

The second purpose of the current study was to determine whether ON symptomatology is related to levels of satisfaction in one's romantic relationships. As expected, symptomatology was negatively correlated with relationship satisfaction among participants who reported being in a committed relationship, and this correlation was most notable for those whose agency was unmitigated, characterized by selfishness and avoidance of others. Extending from the previous finding, perhaps people with $\mathrm{ON}$ are so focused on themselves, including their own ideals of perfect health, that they do not fully identify as one part of a whole unit or relationship, which in turn may lead to relatively poor relationship health and satisfaction. Moreover, past research shows that ON symptomatology is associated with obsessive-compulsiveness [4] [5] [6] [7] [8], perfectionism and narcissism [13], and neuroticism [7] [14], and each of these personality traits are predictive of poor relationship health and satisfaction [10] [11] [12] [15]-[22]. Essentially, with $\mathrm{ON}$, the obsessive desire to maintain unreasonably perfect standards through rigid behavior seems to take precedence over interpersonal relationships with partners who do not share the same ideals and behavioral tendencies toward perfect physical health.

As with any research, this study had its limitations. First, all measures were self-report surveys that may be susceptible to social desirability bias, particularly on the eating habits questionnaire, whereby participants could have provided responses that reflect healthier eating habits than their actual behaviors. However, the fact that the survey responses were anonymous should have reduced the likelihood of any significant bias impacting the study's results. Second, this study did not control for levels of key variables beyond agency and communion, such as narcissism and neuroticism. Although it would be difficult to parse out the eating thoughts and behaviors of ON from the affect and personality profile that is associated with ON, measuring these variables would allow for an assessment of which component of $\mathrm{ON}$ is the biggest contributor to relationship dissatisfaction. Third, although the sample was quite large and ethnically diverse, it was 
limited by convenience of available participants enrolled in psychology courses (for which women comprise the majority of students) at a university in central Texas. Future research on relationship satisfaction with ON should recruit participants from other geographical regions that include those with lower levels of obesity, from other courses that include nutrition and health profession courses, from community settings that include health centers and that would offer a wider age range, and from eating disorder clinics. These recruitment measures would allow for greater generalization across the population, as well as increase the number of participants who meet the diagnostic criteria for ON [2] [3].

\section{Conclusion}

According to clinicians and researchers, ON diagnosis necessitates both 1) an obsessive focus and compulsive behavior regarding what patients deem healthy eating, and 2) resulting clinical impairment [2] [3]. The proposed criteria for clinical impairment include malnutrition or other medical complications arising from their severe dietary restrictions, impairment of social or academic/vocational functioning secondary to their inflexible dietary thoughts and behaviors, and their self-worth being solely tied to compliance with their rigid diet. The current study supports the criterion of impaired social functioning, with its finding that greater ON symptomatology was associated with lower levels of satisfaction in one's romantic relationships. Moreover, this impairment was greatest for individuals scoring high on the trait unmitigated agency, reflecting an extreme focus on oneself to the exclusion of others. When appropriate, couplescounseling therapists should consider how the mindset of patients with ON may contribute to poor relationship health and satisfaction, and they should incorporate nutrition counseling to help overcome ON alongside making improvements in their interpersonal relationships, the result being better physical, mental, and social health.

\section{Conflicts of Interest}

The authors declare no conflicts of interest regarding the publication of this paper.

\section{References}

[1] Bratman, S. and Knight, D. (2000) Health Food Junkies: Overcoming the Obsession with Healthful Eating. Broadway Books, New York.

[2] Dunn, T.M. and Bratman, S. (2016) On Orthorexia Nervosa: A Review of the Literature and Proposed Diagnostic Criteria. Eating Behaviors, 21, 11-17.

https://doi.org/10.1016/j.eatbeh.2015.12.006

[3] Moroze, R.M., Dunn, T.M., Holland, J.C., Yager, J. and Weintraub, P. (2015) Microthinking about Micronutrients: A Case of Transition from Obsessions about Healthy Eating to Near-Fatal "Orthorexia Nervosa" and Proposed Diagnostic Criteria. Psychosomatics, 56, 397-403. https://doi.org/10.1016/j.psym.2014.03.003

[4] Arusoglu, G., Kabakci, E., Koksal, G. and Merdol, T.K. (2008) Orthorexia Nervosa 
and Adaptation of ORTO-11 into Turkish. Turkish Journal of Psychiatry, 19, 283-291.

[5] Asil, E. and Surucuoglu, M.S. (2015) Orthorexia Nervosa in Turkish Dieticians. Ecology of Food and Nutrition, 54, 303-313.

https://doi.org/10.1080/03670244.2014.987920

[6] Gezer, C. and Kabaran, S. (2013) The Risk of Orthorexia Nervosa for Female Students Studying Nutrition and Dietetics. SDU Journal of Health Science Institute, 4, 14-22.

[7] Gleaves, D.H., Graham, E.C. and Ambwani S. (2013) Measuring “Orthorexia:” Development of the Eating Habits Questionnaire. International Journal of Educational and Psychological Assessment, 12, 1-18.

[8] Koven, N.S. and Senbonmatsu, R. (2013) A Neuropsychological Evaluation of Orthorexia Nervosa. Open Journal of Psychiatry, 3, 214-222. https://doi.org/10.4236/ojpsych.2013.32019

[9] Oberle, C.D., Watkins, R.S. and Burkot, A.J. (2018) Orthorexic Eating Behaviors Related to Exercise Addiction and Internal Motivations in a Sample of University Students. Eating and Weight Disorders, 23, 67-74. https://doi.org/10.1007/s40519-017-0470-1

[10] Abbey, R.D., Clopton, J.R. and Humphreys, J.D. (2007) Obsessive-Compulsive Disorder and Romantic Functioning. Journal of Clinical Psychology, 63, 1181-1192. https://doi.org/10.1002/jclp.20423

[11] Solem, S., Haaland, A.T., Hagen, K., Launes, G., Hansen, B., Vogel, P.A. and Himle, J.A. (2015) Interpersonal Style in Obsessive-Compulsive Disorder. The Cognitive Behaviour Therapist, 8, 1-17. https://doi.org/10.1017/S1754470X15000719

[12] Wiltgen, A., Adler, H., Smith, R., Rufino, K., Frazier, C., Shepard, C., Booker, K., Simmons, D., Richardson, L., Allen, J.G. and Fowler, J.C. (2015) Attachment Insecurity and Obsessive-Compulsive Personality Disorder among Inpatients with Serious Mental Illness. Journal of Affective Disorders, 174, 411-415. https://doi.org/10.1016/j.jad.2014.12.011

[13] Oberle, C.D., Samaghabadi, R.O. and Hughes, E.M. (2017) Orthorexia Nervosa: Assessment and Correlates with Gender, BMI, and Personality. Appetite, 108, 303-310. https://doi.org/10.1016/j.appet.2016.10.021

[14] Forester, D.S. (2014) Examining the Relationship between Orthorexia Nervosa and Personality Traits (Unpublished master's thesis). California State University, Stanislaus.

[15] Mackinnon, S.P., Sherry, S.B., Antony, M.M., Stewart, S.H., Sherry, D.L. and Hartling, N. (2012) Caught in a Bad Romance: Perfectionism, Conflict, and Depression in Romantic Relationships. Journal of Family Psychology, 26, 215-225. https://doi.org/10.1037/a0027402

[16] Stoeber, J. (2012) Dyadic Perfectionism in Romantic Relationships: Predicting Relationship Satisfaction and Longterm Commitment. Personality and Individual Differences, 53, 300-305. https://doi.org/10.1016/j.paid.2012.04.002

[17] Campbell, K.W. and Foster, C.A. (2002) Narcissism and Commitment in Romantic Relationships: An Investment Model Analysis. Personality and Social Psychology Bulletin, 28, 484-495. https://doi.org/10.1177/0146167202287006

[18] Foster, C.A. (2008) Incorporating Personality into the Investment Model: Probing Commitment Processes across Individual Differences in Narcissism. Journal of Social and Personal Relationships, 25, 211-223. 
https://doi.org/10.1177/0265407507087956

[19] Foster, C.A. and Campbell, K.W. (2005) Narcissism and Resistance to Doubts about Romantic Partners. Journal of Research in Personality, 39, 550-557. https://doi.org/10.1016/j.jrp.2004.11.001

[20] Braithwaite, S.R., Mitchell, C.M., Selby, E.A. and Finchman, F.D. (2016) Trait Forgiveness and Enduring Vulnerabilities: Neuroticism and Catastrophizing Influence Relationship Satisfaction via Less Forgiveness. Personality and Individual Differences, 94, 237-246. https://doi.org/10.1016/j.paid.2015.12.045

[21] Dyrenforth, P.S., Kashy, D.A., Donnellan, M.B. and Lucas, R.E. (2010) Predicting Relationship and Life Satisfaction from Personality in Nationally Representative Samples from Three Countries: The Relative Importance of Actor, Partner, and Similarity Effects. Journal of Personality and Social Psychology, 99, 690-702. https://doi.org/10.1037/a0020385

[22] Malouff, J.M., Thorsteinsson, E.B., Schutte, N.S., Bhullar, N. and Rooke, S.E. (2009) The Five-Factor Model of Personality and Relationship Satisfaction of Intimate Partners: A Meta-Analysis. Journal of Research in Personality, 44, 124-127. https://doi.org/10.1016/j.jrp.2009.09.004

[23] Oberle, C.D., Dooley, A.A. and Nagurney, A.J. (2017) Predicting Perceived Infidelity from Gender and Interpersonal Traits. Sexual and Relationship Therapy, 32, 89-101. https://doi.org/10.1080/14681994.2016.1196290

[24] Oberle, C.D., Nagurney, A.J. and Jones, C.B. (2016) Predicting Safe Sex Practices from Gender-Related Interpersonal Variables. Health Psychology and Behavioral Medicine, 4, 114-123. https://doi.org/10.1080/21642850.2016.1183203

[25] Hagemeyer, B., Neberich, W., Asendorpf, J.B. and Neyer, F.J. (2012) (In)congruence of Implicit and Explicit Communal Motives Predicts the Quality and Stability of Couple Relationships. Journal of Personality, 81, 390-402. https://doi.org/10.1111/jopy.12016

[26] Hagemeyer, B. and Neyer, F.J. (2012) Assessing Implicit Motivational Orientations in Couple Relationships: Partner-Related Agency and Communion Test (PACT). Psychological Assessment, 24, 114-128. https://doi.org/10.1037/a0024822

[27] Le, B.M., Impett, E.A., Lemay, E.P., Jr., Muise, A. and Tskhay, K.O. (2018) Communal Motivation and Well-Being in Interpersonal Relationships: An Integrative Review and Meta-Analysis. Psychological Bulletin, 144, 1-25. https://doi.org/10.1037/bul0000133

[28] Young, D.M., Moss-Racusin, C.A. and Sanchez, D.T. (2014) Implicit Agency, Communality, and Perceptual Congruence in Couples: Implications for Relationship Health. Journal of Experimental Social Psychology, 55, 133-138. https://doi.org/10.1016/j.jesp.2014.06.010

[29] Hagemeyer, B., Schonbrodt, F.D., Neyer, F.J., Neberich, W. and Asendorpf, J.B. (2015) When "Together" Means "Too Close": Agency Motives and Relationship Functioning in Coresident and Living-Apart-Together Couples. Journal of Personality and Social Psychology, 109, 813-835. https://doi.org/10.1037/pspi0000031

[30] Fidan, T., Ertekin, V., Isikay, S. and Kirpinar, I. (2010) Prevalence of Orthorexia among Medical Students in Erzurum, Turkey. Comprehensive Psychiatry, 51, 49-54. https://doi.org/10.1016/j.comppsych.2009.03.001

[31] Segura-Garcia, C., Papaianni, M.C., Caglioti, F., Procopio, L., Nistico, C.G., Bombardiere, L., Ammendolia, A., Rizza, P., De Fazio, P. and Capranica, L. (2012) Orthorexia Nervosa: A Frequent Eating Disorder Behavior in Athletes. Eating and Weight Disorders, 17, 223-233. 
[32] Segura-Garcia, C., Ramacciotti, C., Rania, M., Aloi, M., Caroleo, M., Bruni, A., Gazzarrini, D., Sinopoli, F. and De Fazio, P. (2015) The Prevalence of Orthorexia Nervosa among Eating Disorder Patients after Treatment. Eating and Weight Disorders, 20, 161-166. https://doi.org/10.1007/s40519-014-0171-y

[33] Spence, J.T., Helmreich, R.L. and Holahan, C.K. (1979) Negative and Positive Components of Psychological Masculinity and Femininity and Their Relationships to Self-Reports of Neurotic and Acting out Behaviors. Journal of Personality and Social Psychology, 37, 1673-1682. https://doi.org/10.1037/0022-3514.37.10.1673

[34] Fritz, H.L. and Helgeson, V.S. (1998) Distinctions of Unmitigated Communion from Communion: Self-Neglect and Overinvolvement with Others. Journal of Personality and Social Psychology, 75, 121-140. https://doi.org/10.1037/0022-3514.75.1.121

[35] Thornton, V.L. and Nagurney, A.J. (2011) What Is Infidelity? Perceptions Based on Biological Sex and Personality. Psychology Research and Behavior Management, 4, 51-58.

[36] Hendrick, S.S. (1988) A Generic Measure of Relationship Satisfaction. Journal of Marriage and the Family, 50, 93-98. https://doi.org/10.2307/352430

[37] Helgeson, V.S. and Fritz, H.L. (1999) Unmitigated Agency and Unmitigated Communion: Distinctions from Agency and Communion. Journal of Research in Personality, 33, 131-158. https://doi.org/10.1006/jrpe.1999.2241 